\title{
Photovoltaic System Design and Performance
}

\author{
Wilfried van Sark $(D)$ \\ Utrecht University, Copernicus Institute, Princetonlaan 8a, 3584 CB Utrecht, The Netherlands; \\ w.g.j.h.m.vansark@uu.nl
}

Received: 7 February 2019; Accepted: 8 May 2019; Published: 14 May 2019

\begin{abstract}
This editorial summarizes the collection of papers in the Special Issue entitled Photovoltaic System Design and Performance, which was published in MDPI's Energies journal. Papers on this topic were submitted in 2017 and 2018, and a total of 21 papers were published. Main topics included data analysis for optimal performance and fault analysis, causes for energy loss, and design and integration issues. The papers in this Special Issue demonstrate the importance of designing and properly monitoring photovoltaic systems in the field in order to ensure maintaining good performance.
\end{abstract}

Keywords: photovoltaic (PV) system design; monitoring of PV systems; performance analysis; mapping performance; performance variability; system malfunction detection

\section{Introduction}

Photovoltaic (PV) solar technology grew rapidly and continuously in the past decades, leading to $\sim 400$ GWp installed capacity globally [1], and this led to enormous price reductions. The strength of the technology is its modular design, and PV power plants range from a few PV modules $(\sim 1 \mathrm{kWp})$ to millions ( 250 MWp). Design of such systems depends on the scale level; residential systems are typically roof-based, either flat or tilted, while large systems allow to design for maximum annual yield but also require intricate electrical layouts with multiple inverters and connections to medium-voltage transmission networks. Additionally, operation is scale-dependent. In residential areas, non-ideal tilts and potential shading will lower annual yields, and designs to minimize these losses were developed, using, e.g., power optimization per module. Monitoring of such small systems is rare, as economic loss due to malfunction is relatively low. Large-scale systems have proper supervisory control and data acquisition (SCADA) systems to ensure maximum economic benefit, which is of importance to investors.

This Special Issue solicited papers with original research and studies related to the abovementioned topics, including, but not limited to, PV system design on residential and larger scales, methods for operational control and analysis, failure detection, performance analysis of systems, mapping performance differences, performance variability, and degradation of systems and modules. Papers selected for this Special Issue were subject to a rigorous peer review procedure with the aim of rapid and wide dissemination of research results, developments, and applications.

The response to the call for papers led to 28 submitted papers, of which 21 (75\%) were accepted and seven $(25 \%)$ rejected. The geographical distribution of the (first) author covers all continents, and is built as follows: Austria (one paper), Brazil (one), China (three), Colombia (two), Germany (one), Italy (one), Korea (two), Romania (one), Portugal (one), Spain (one), Slovenia (one), the Netherlands (four), United Kingdom (UK; one), and United States of America (USA; one). 


\section{Content of the Special Issue}

The 21 papers collected in this Special Issue can broadly be divided into the following fields: (a) data analysis for optimal performance and fault analysis, (b) causes for energy loss, and (c) design and integration issues. They will be described in the following subsections.

\subsection{Data Analysis for Optimal Performance}

In the design phase of PV systems, yield predictions are made based on the typical weather data available or derived for the specific installation site. During operation, monitoring of yield is a necessity to demonstrate that the yield predictions were correct, which will satisfy investors. In addition to proper design and quality-controlled installation of the PV system, operation and maintenance $(\mathrm{O} \& \mathrm{M})$ procedures should be in place that include adequate intervention after a yield loss is detected. Automatic detection of the cause of the yield loss will decrease downtime of a system, thus lowering potential economic loss. Several papers in this Special Issue addressed various aspects of O\&M procedures. Santiago et al. [2] proposed a graphical procedure that supports performance analysis of PV plant operations, without additional costs. It is based on inverter data, which are automatically processed. Visualization using color maps or heat maps of direct current (DC) energy generated in the PV plant are shown as a function of day in the year and time of day, which is extremely insightful, as anomalies can be detected clearly. The usefulness of the method is demonstrated in a small PV plant of $17.8 \mathrm{kWp}$ in size located in Córdoba, Spain, for a period of three years. The average daily performance ratio varied between 0.6 and 0.9 , with highest values in winter. Detailed analysis of inverter data further showed that the presence of shadows could be easily detected, in particular the hours and days for which the system was mainly affected.

On a larger scale, Kausika et al. [3] and Moraitis et al. [4] demonstrated the usefulness of applying geographical information systems (GIS) in PV performance analysis on a multi-country and regional level. Maps were constructed for several European countries based on annual yield data from more than 30,000 PV systems. Color mapping and mapping differences between yields in different years assisted in identifying potential problems in PV systems across countries or regions. Moraitis et al. [4] provided an even more detailed analysis, showing the performance differences between PV system installed in rural and urban areas, and related these differences to the urban compactness causing more shading on systems than in rural areas. A seasonal dependence further corroborated the finding that shading is the cause for lower performance in urban areas.

Zhao et al. [5] proposed a novel fault diagnosis method for PV systems based on several fuzzy algorithms. The method was shown by simulation analyses to effectively detect short-circuit, open-circuit, partial occlusion, and other faults. Actual experiments with a 9.6-kWp PV system in the field further demonstrated that the method yields correct and effective fault detection, confirming the correctness and effectiveness of the proposed method, and that the method can complete the PV array diagnosis. The method was inspired by the notion that the unpredictability of faults can best be addressed using fuzzy theory.

At normal operation, the energy yield of PV systems is (nearly) linearly related to reference data such as irradiance or yield of neighboring PV systems. Tsafarakis et al. [6] described a new data analysis method that automatically distinguishes measurements that fit to a near-linear relationship (defined as inliers) from those which do not (outliers). The method, thus, can be used to detect and exclude any data input anomalies, and to detect and separate measurements where the PV system is functioning properly from the measurements characteristic for malfunctioning. The method was demonstrated in actual experimental data, showing that peer-to-peer comparison of yield is better than using irradiance data, whether from a pyranometer or derived from satellite images.

Although PV energy yield depends directly on solar irradiance and module temperature, Vergura [7] ignored these parameters and compared the energy performance of PV systems, or rather arrays of panels in the same 49-kWp plant in southern Italy, using several statistical methods including analysis of variance (ANOVA) in combination with various tests. This actually is a form of peer-to-peer 
comparison, and it was designed since the cost of advanced monitoring equipment is considered too high for the size of the PV plant. It was shown that these methods are effective in finding abnormal operating conditions.

Baschel et al. [8] reported on component reliability in large-scale PV systems and the effect on performance, based on a large operational dataset of failure rates for periods of 3-5 years. Impact assessment was performed using a fault tree analysis, as well as a failure mode and effects analysis, which was used to rank failures in term of occurrence and severity. Reduced energy yields were estimated based on actual failure probabilities. For example, transformer failures, while rare, lead to energy loss due to the long repair periods. Thus, transformer and inverter problems are responsible for two-thirds of the total energy loss.

Detailed analysis of performance of PV systems may require knowledge of detailed PV module parameters, such as diode parameters. As the current-voltage (I-V) characteristics involve an implicit function, fitting is needed to find parameters. For many decades, methods to solve this ere proposed. Kang et al. [9] newly proposed methods based on cuckoo search algorithms. An improved version for both single- and double-diode models was developed and tested using experimental I-V data. It was shown that the new method outperforms state-of-the-art algorithms, and finds parameters effectively.

\subsection{Causes for Energy Loss}

Several causes for energy loss can be identified. This subsection shows the effects of shadows and a solution to mitigate them, as well as the effects of soiling and degradation. Identification of the latter is possible using various imaging techniques.

Gutiérrez Galeano et al. [10] presented a simplified approach using a shading ratio to model and analyze the performance of partially shaded PV modules. A model was derived using well-known current-voltage characteristics, in which the shape and opacity of a shaded area are integrated. The method was developed to improve the detection of shaded PV systems, and it was experimentally validated. In order to mitigate shadow-induced losses in PV modules, Mirbagheri Golroodbari et al. [11] developed a smart PV module architecture consisting of 60 silicon solar cells. This module optimally consists of ten groups of six series-connected solar cells in parallel to a DC-DC buck converter. A model was developed that allows time-dependent simulations of moving shadows of poles and random shading patterns over the module. Compared to an ideal module, as well as standard series-connected or parallel-connected modules, the smart architecture outperforms the series-connected one by nearly $50 \%$.

Another problem in PV system performance is soiling on the modules. Conceição et al. [12] presented the effect of soiling in Alentejo and Évora in Portugal on PV performance, and discussed the seasonal variation and the type of soiling. Sand from the Sahara was identified as soiling, in addition to pollen, especially in spring. A so-called soiling ratio index was defined using maximum power and short-circuit current of PV panels, and a detailed materials analysis was performed using scanning electron microscopy and energy-dispersive $\mathrm{x}$-ray spectroscopy. The highest soiling rate of $4.1 \% / \mathrm{month}$ was found in spring, while the summer and fall months showed $1.9 \% /$ month and $1.6 / \%$ month, respectively. This spring increase was due to the presence of pollen, in addition to inorganic materials. The effect of pollen was larger than that of organic materials, due to their larger particle size.

Degradation of solar cells as a result of various causes is known to affect the capacitance of solar cells. Cotfas et al. [13] demonstrated a simple technique to measure solar cell capacitance using an inductor, thus forming a resistor/inductor/capacitor (RLC) circuit. When connecting the inductor to the cell, oscillations in voltage and current appear, which are damped after some time. The frequency of these oscillations can be found using RLC circuit behavior, from which the capacitance of the cell is derived. Additional experiments showed that the capacitance increases with irradiance, as well as with temperature.

Eder et al. [14] studied the aging of PV test modules by comparing intact modules with modules with deliberately generated failures, i.e., micro-cracks, cell cracks, glass breakage, and connection 
defects. These modules were tested under different conditions in climate chambers and outdoors to be able to follow the propagation of stress-induced defects and their effect on performance. Module characterization was performed using electrical measurements and electroluminescence (EL), as well as using fluorescence imaging for the detection of aging effects in encapsulation materials of the modules. It was found that modules with mechanical failures were unaffected, while the pre-test presence of micro-cracks led to a higher rate of degradation after testing. Elevated temperature and irradiation were found to induce fluorescence effects in polymeric encapsulants after about one year of outdoor testing. Fluorescence imaging is a useful tool in detecting permeation of oxygen through the back sheet, which can be identified as bleaching of the fluorescence of the encapsulant top layer between the cells, above cell cracks.

While electroluminescence (EL) is widely used to qualitatively map electronic properties of PV modules, Kropp et al. [15] presented a new approach which allows for a quantitative assessment. The so-called "EL power prediction of modules" (ELMO) method is based on using two electroluminescence images to determine the electrical loss of damaged PV modules. The EL images are converted into spatially resolved series resistance images, and color-coded maps reveal the location of damages in the module. The method is also applicable for parallel resistance mapping, which was demonstrated in the analysis of potential-induced degradation.

\subsection{Design and Integration Issues}

Maximum power point tracking (MPPT) devices and algorithms are essential in maximizing power output of PV modules and systems. Robles Algarín et al. [16] discussed the common approach based on the so-called perturb-and-observer $(\mathrm{P} \& \mathrm{O})$ algorithm, and showed that this may lead to oscillation issues around the operating point. They suggested an alternative way, i.e., to use a fuzzy controller for finding the maximum power point. A simulation model was designed for a PV panel, a buck converter, and a fuzzy controller, and the authors showed that their method with the fuzzy controller outperforms the common $\mathrm{P} \& \mathrm{O}$ approach, with faster settling time, lower power loss, and oscillations around the operating point.

Forecasting of energy generation of PV systems is important for integration of PV in the electricity grid, as it facilitates power management in the local grid. Accurate forecasting requires information about expected solar irradiance, which is not readily available. Therefore, Brecl and Topič [17] developed a method based on only weather forecast data, and solar irradiance was simulated based on discrete weather class values. The simple approach led to a root-mean-square error of measured and forecasted power data of $65 \%$, while the correlation in terms of $R^{2}$ was high at 0.85 .

Grid connection of a PV system may suffer from stability issues, as Huang et al. [18] argued. They provided a stability analysis based on a single-phase two-stage (modules, inverter) PV system connected to the grid. The nonlinearity of PV system response to irradiation poses a problem in linear system theory, which is usually used in grid stability analyses. Therefore, Huang et al. [18] developed a mathematical model addressing this issue. As the time dependence of current and voltage is the main problem in the stability analysis, a transformation was used to make the problem time-invariant. Results revealed that the mathematical model performs well compared to standard power simulation models (PSIM [19]).

Large PV power plants will not always operate at maximum power, and this allows inverters to provide reactive power support to the grid. Lourenço et al. [20] presented an evaluation method for reactive power support and associated cost. The method helps PV power plant owners optimize their bidding strategies in the reactive power market. At low irradiance, reactive power support can be large, while, at high irradiance, this is limited. Costs for providing reactive power were analyzed, as well as potential revenues in the Brazilian market, which are about $25 \%$ more than costs.

Kim et al. [21] described the design and construction of a floating PV system using fiber-reinforced polymer parts. The system consisted of modular structures connected by means of hinges, and anchored to shore. The 1-MWp plant is located in Dangjin City, Korea, at the waterway of the cooling water intake 
channel of a thermoelectric power plant, and it covers an area of about $21,000 \mathrm{~m}^{2}$. Safety aspects were designed such that they comply with relevant design codes. The design also contains parts for electrical equipment (inverters, etc.) and pontoons that allow maintenance personnel to access the various areas of the system. Cost are expected to be lower compared to steel- or aluminum-based constructions.

Another contribution to floating PV was provided by Charles Lawrence Kamuyu et al. [22], who presented a multiple linear regression method using independent parameters of irradiance, ambient temperature, and wind speed to explain observed module temperature in a floating PV system. Interestingly, adding the water temperature as parameter slightly increased the error between observed and modeled temperature. The found correlation could be used to explain the $\sim 10 \%$ increased annual yield of floating PV systems in Korea compared to roof-top systems.

Alshayeb et al. [23] reported on a year-long experimental study in which they compared the performance of a 4.3-kWp PV system over a green roof and a black roof. A detailed analysis of temperatures underneath the panels, in between panels and roof, and of ambient temperature helped explain the difference in energy yield between the green and black roof, which was maximally about $5 \%$ in favor of the green roof, with an average annual benefit of $1.4 \%$.

\section{Conclusions}

The papers published as part of this Special Issue demonstrate the importance of and scientific progress in the design and performance of PV systems. The state of the art in the three fields of data analysis for optimal performance, causes for energy loss, and design and integration issues is evidenced in the content of the 21 papers from all over the world. It is clear that challenges do exist, which can be addressed in the near future. With the ever-increasing deployment of PV systems, proper design and monitoring, as well as fast and early detection of malfunctions, are prerequisites for PV to play a major role in future electricity systems.

Author Contributions: W.v.S. organized the Special Issue and wrote the manuscript.

Funding: This research was part of the IEA-PVPS Task 13 "Performance and Reliability of Photovoltaic Systems" [24] and the COST Action PEARL-PV "Performance and Reliability of Photovoltaic Systems: Evaluations of Large-Scale Monitoring Data" [25].

Acknowledgments: The guest editor would like to thank the authors for submitting their excellent contributions to this Special Issue. Furthermore, the present Special Issue would not have been possible without the expert reviewers that carefully evaluated the manuscripts and provided helpful comments and suggestions for improvements. A special thank you is in order for the editors and the MDPI team for their outstanding management of this Special Issue.

Conflicts of Interest: The author declares no conflict of interest.

\section{References}

1. IEA. 2018: Snapshot of global photovoltaic markets: Report IEA PVPS T1-33:2018. 2018. Available online: http://www.iea-pvps.org/fileadmin/dam/public/report/statistics/IEA-PVPS_-_A_Snapshot_ of_Global_PV_-_1992-2017.pdf (accessed on 22 January 2019).

2. Santiago, I.; Trillo Montero, D.; Luna Rodríguez, J.; Moreno Garcia, I.; Palacios Garcia, E. Graphical Diagnosis of Performances in Photovoltaic Systems: A Case Study in Southern Spain. Energies 2017, 10, 1964. [CrossRef]

3. Kausika, B.; Moraitis, P.; van Sark, W. Visualization of Operational Performance of Grid-Connected PV Systems in Selected European Countries. Energies 2018, 11, 1330. [CrossRef]

4. Moraitis, P.; Kausika, B.; Nortier, N.; van Sark, W. Urban Environment and Solar PV Performance: The Case of the Netherlands. Energies 2018, 11, 1333. [CrossRef]

5. Zhao, Q.; Shao, S.; Lu, L.; Liu, X.; Zhu, H. A New PV Array Fault Diagnosis Method Using Fuzzy C-Mean Clustering and Fuzzy Membership Algorithm. Energies 2018, 11, 238. [CrossRef]

6. Tsafarakis, O.; Sinapis, K.; van Sark, W. PV System Performance Evaluation by Clustering Production Data to Normal and Non-Normal Operation. Energies 2018, 11, 977. [CrossRef]

7. Vergura, S. Hypothesis Tests-Based Analysis for Anomaly Detection in Photovoltaic Systems in the Absence of Environmental Parameters. Energies 2018, 11, 485. [CrossRef] 
8. Baschel, S.; Koubli, E.; Roy, J.; Gottschalg, R. Impact of Component Reliability on Large Scale Photovoltaic Systems' Performance. Energies 2018, 11, 1579. [CrossRef]

9. Kang, T.; Yao, J.; Jin, M.; Yang, S.; Duong, T. A Novel Improved Cuckoo Search Algorithm for Parameter Estimation of Photovoltaic (PV) Models. Energies 2018, 11, 1060. [CrossRef]

10. Gutiérrez Galeano, A.; Bressan, M.; Jiménez Vargas, F.; Alonso, C. Shading Ratio Impact on Photovoltaic Modules and Correlation with Shading Patterns. Energies 2018, 11, 852. [CrossRef]

11. Mirbagheri Golroodbari, S.; de Waal, A.; van Sark, W. Improvement of Shade Resilience in Photovoltaic Modules Using Buck Converters in a Smart Module Architecture. Energies 2018, 11, 250. [CrossRef]

12. Conceição, R.; Silva, H.; Mirão, J.; Collares-Pereira, M. Organic Soiling: The Role of Pollen in PV Module Performance Degradation. Energies 2018, 11, 294. [CrossRef]

13. Cotfas, P.; Cotfas, D.; Borza, P.; Sera, D.; Teodorescu, R. Solar Cell Capacitance Determination Based on an RLC Resonant Circuit. Energies 2018, 11, 672. [CrossRef]

14. Eder, G.; Voronko, Y.; Hirschl, C.; Ebner, R.; Újvári, G.; Mühleisen, W. Non-Destructive Failure Detection and Visualization of Artificially and Naturally Aged PV Modules. Energies 2018, 11, 1053. [CrossRef]

15. Kropp, T.; Schubert, M.; Werner, J. Quantitative Prediction of Power Loss for Damaged Photovoltaic Modules Using Electroluminescence. Energies 2018, 11, 1172. [CrossRef]

16. Robles Algarín, C.; Taborda Giraldo, J.; Rodríguez Álvarez, O. Fuzzy Logic Based MPPT Controller for a PV System. Energies 2017, 10, 2036. [CrossRef]

17. Brecl, K.; Topič, M. Photovoltaics (PV) System Energy Forecast on the Basis of the Local Weather Forecast: Problems, Uncertainties and Solutions. Energies 2018, 11, 1143. [CrossRef]

18. Huang, L.; Qiu, D.; Xie, F.; Chen, Y.; Zhang, B. Modeling and Stability Analysis of a Single-Phase Two-Stage Grid-Connected Photovoltaic System. Energies 2017, 10, 2176. [CrossRef]

19. PSIM power system simulation. Available online: https://powersimtech.com/products/psim/ (accessed on 5 February 2019).

20. Lourenço, L.; Monaro, R.; Salles, M.; Cardoso, J.; Quéval, L. Evaluation of the Reactive Power Support Capability and Associated Technical Costs of Photovoltaic Farms' Operation. Energies 2018, 11, 1567. [CrossRef]

21. Kim, S.; Yoon, S.; Choi, W. Design and Construction of 1 MW Class Floating PV Generation Structural System Using FRP Members. Energies 2017, 10, 1142. [CrossRef]

22. Charles Lawrence Kamuyu, W.; Lim, J.; Won, C.; Ahn, H. Prediction Model of Photovoltaic Module Temperature for Power Performance of Floating PVs. Energies 2018, 11, 447. [CrossRef]

23. Alshayeb, M.; Chang, J. Variations of PV Panel Performance Installed over a Vegetated Roof and a Conventional Black Roof. Energies 2018, 11, 1110. [CrossRef]

24. IEA-PVPS-Task 13. Available online: http://www.iea-pvps.org/index.php?id=57 (accessed on 5 February 2019).

25. COST Action PEARL-PV. Available online: https://www.pearlpv-cost.eu (accessed on 5 February 2019).

(C) 2019 by the author. Licensee MDPI, Basel, Switzerland. This article is an open access article distributed under the terms and conditions of the Creative Commons Attribution (CC BY) license (http://creativecommons.org/licenses/by/4.0/). 